\title{
Persepsi dan preferensi masyarakat terhadap taman rekreasi bantaran Sungai Loloan Sanur
}

\author{
I Gede Angga Pradipta ${ }^{1}$, Sang Made Sarwadana ${ }^{1}$, Ni Luh Made Pradnyawathi $2^{\star}$
}

1. Prodi Arsitektur Pertamanan, Fakultas Pertanian, Universitas Udayana, Indonesia

2. Program Studi Agroekoteknologi, Fakultas Pertanian, Universitas Udayana, Indonesia

*E-mail: pradnyawathi@unud.ac.id

\begin{abstract}
Public Perception and Preference of Loloan Riverbank Recreational Park Sanur. Denpasar is a developing city. Like other developing cities in Indonesia, Denpasar City continues to carry out development in various aspects, one of which is the construction of a recreational park. Servers as a recreational facility and social interaction for the people of Denpasar City. One of the recreational parks being promoted is Recreational Park of Loloan Riverbanks located in Sanur Village. To maximize functionality and improve quality of The Recreational Park Loloan Riverbanks, therefore should be done research on this Recreational Park Loloan Riverbanks to know how perception and preference the community as a user of recreational park. This research used survey method with data collection techniques is observation, interview and questionnaire wich amounted to 30 copies for 30 respondent. Result of people's perceptions showed Recreational Park of Loloan Riverbanks serves as a cheap recreational place and a cheap sport venue for the people's of Denpasar City. Result of people's preference showed addition of recreational park support facilities will lead to increased levels of enjoyment and visitor satisfaction from the Recreational Park of Loloan Riverbank. Public perception and preference of The Recreational Park Loloan Riverbanks used as information and references to the manager or related parties that play a role in managing The Recreational Park Loloan Riverbanks Denpasar City, so that later The Recreational Park Loloan Riverbanks will be liked by the community of Denpasar City.
\end{abstract}

Keywords: community perceptions and preferences, green public open space, the recreational park of Loloan riverbanks

\section{Pendahuluan}

Kota Denpasar merupakan kota yang sedang berkembang di Indonesia. Kota Denpasar saat ini terus melakukan pembangunan di berbagai aspek, salah satunya pembangunan taman rekreasi yang berfungsi sebagai sarana rekreasi dan sarana interaksi sosial bagi masyarakat Kota Denpasar. Taman rekreasi di Kota Denpasar ini umumnya dibangun pada taman-taman Kota Denpasar saja seperti Taman Kota Lumintang, Lapangan Gusti Made Agung atau yang sering dikenal dengan nama Lapangan Puputan Badung dan Lapangan Niti Mandala Renon, namun baru baru ini telah dibangun taman rekreasi yang unik, biasanya taman rekreasi dibangun pada lahan luas di tengah-tengah kota, namun taman rekreasi ini dibangun di bantaran sungai. Taman rekreasi ini bernama taman rekreasi bantaran Sungai Loloan (Tukad Loloan) yang terletak di kawasan Pantai Mertasari Desa Sanur Kauh Kecamatan Denpasar Selatan.

Dengan dibangunnya taman rekreasi bantaran Sungai Loloan, pemerintah Kota Denpasar menginginkan adanya aktivitas mayarakat yang positif pada taman rekreasi bantaran Sungai Loloan, seperti melakukan kegiatan olahraga jogging, melakukan aktivitas sosial dengan berinteraksi sesama pengunjung, agar nantinya kesan seram atau angker pada sungai menjadi hilang karena ramainya aktivitas masyarakat pada taman rekreasi bantaran Sungai Loloan tersebut. Panjang taman rekreasi bantaran Sungai Loloan ini $560 \mathrm{~m}$ dan lebar $10 \mathrm{~m}$ dengan luas keseluruhan $5.600 \mathrm{~m}^{2}$.

Untuk memaksimalkan fungsi dan peningkatan kualitas taman rekreasi bantaran sungai maka perlu dilakukan penelitian pada tapak ini untuk mengetahui bagaimana persepsi dan preferensi masyarakat pengguna sarana taman rekreasi tersebut. Persepsi merupakan interpretasi terhadap rangsangan yang diterima dari lingkungan yang bersifat individual (Fitri, 2009) sedangkan preferensi merupakan selera atau 
keinginan individual yang mengasumsikan pilihan realitas ataupun pilihan imajiner yang nantinya akan memenuhi tingkat kesenangan dan kepuasan individual tersebut (Ruily, 2009). Persepsi dan preferensi masyarakat terhadap taman rekreasi bantaran sungai ini digunakan sebagai informasi dan acuan kepada pengelola atau pihak terkait yang memegang peran dalam pengelolaan taman rekreasi bantaran Sungai Kota Denpasar.

Rumusan masalah pada penelitian ini yaitu bagaimana persepsi masyarakat terhadap taman rekreasi di bantaran Sungai Loloan dan apa preferensi masyarakat sebagai pengguna sarana taman rekreasi di bantaran Sungai Loloan. Tujuan dari penelitian ini adalah mengidentifikasi persepsi masyarakat terhadap taman rekreasi di bantaran Sungai Loloan serta mengetahui preferensi masyarakat sebagai pengguna sarana taman rekreasi di bantaran Sungai Loloan.

\section{Metode Penelitian}

\subsection{Tempat dan Waktu Penelitian}

Pelaksanaan kegiatan penelitian dilakukan di bantaran Sungai Loloan, Desa Sanur, Kecamatan Denpasar Selatan, Kota Denpasar, Provinsi Bali. Waktu penelitian dilakukan mulai bulan Maret 2017 sampai bulan agustus 2017.

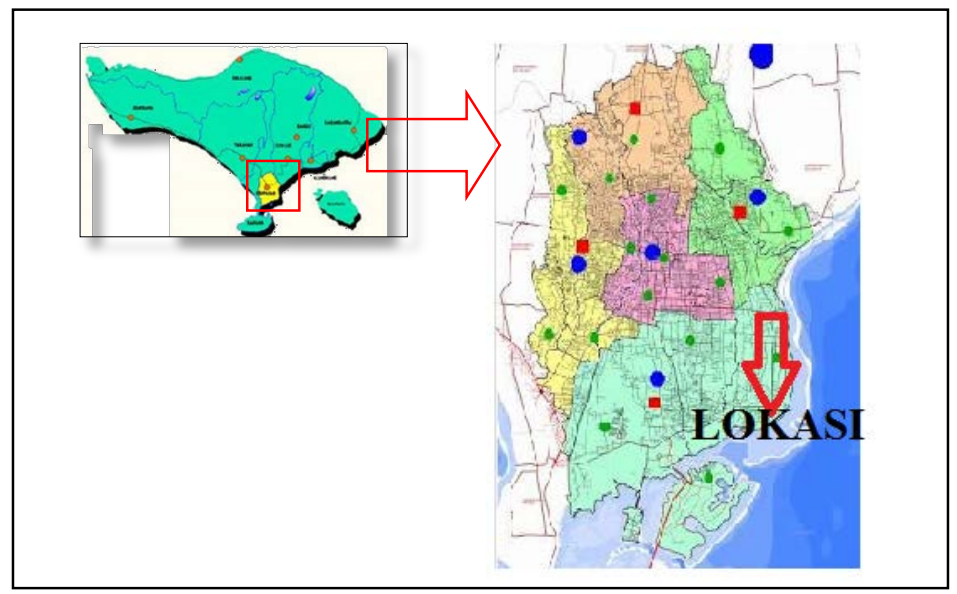

Gambar 1. Lokasi Penelitian

\subsection{Alat Penelitian}

Alat penelitian yang digunakan dalam penelitian ini adalah alat tulis, kamera, lembar kuisioner, lembar wawancara dan laptop dengan perangkat lunak Google Earth, Autocad 2014, Google Sketchup 2015, dan Microsoft Office.

\subsection{Metode Penelitian}

Penelitian dilakukan dengan metode survei, dengan teknik pengumpulan data yaitu dengan observasi, wawancara dan penyebaran kuisioner.

\subsubsection{Data penelitian}

Jenis data yang dikumpulkan dalam penelitian ini berupa data primer dan data sekunder. Data primer berupa pengumpulan data yang diperoleh melalui observasi, wawancara dan penyebaran kuisioner. Data sekunder merupakan data yang diperoleh dari metode studi pustaka dari buku-buku, jurnal, majalah, dan internet.

\subsubsection{Teknik Pengumpulan Data}

Teknik pengumpulan data yang digunakan adalah observasi, wawancara, penyebaran kuisioner dan studi pustaka.

1. Observasi

Observasi merupakan teknik pengumpulan data dengan melakukan pengamatan secara langsung kondisi tapak baik administratif, fisik dan biofisik, fungsional, maupun pengguna untuk mengetahui keadaan dari bantaran Sungai Loloan. 


\section{Wawancara}

Wawancara merupakan teknik pengumpulan data dengan mengadakan tanya jawab langsung terhadap pihak-pihak yang berkaitan dengan penelitian yakni Dinas Pekerjaan Umum Pemerintahan Kota Denpasar sebagai pengelola serta kepala Desa Sanur Kauh dan kelian Banjar Betngandang sebagai tokoh masyarakat di lokasi penelitian.

3. Penyebaran Kuisioner

Penyebaran Kuisioner merupakan teknik pengumpulan data dengan menyebarkan lembaran pertanyaan yang diisi oleh responden. Kuisioner yang disebarkan sebanyak 30 eksemplar, satu eksemplar kuisioner dijawab oleh satu responden, karena asumsi distribusi normal saat perhitungan ketika jumlah sampel mencapai 30 orang (Reimundo, 2014

4. Studi pustaka

Studi pustaka merupakan teknik pengumpulan data dengan mencari data-data yang berhubungan dengan penelitian ini baik diperoleh dari jurnal hasil penelitian, buku-buku, peraturan-peraturan, dan sumbersumber tertulis maupun media internet.

\subsection{Batasan Penelitian}

Penelitian ini dilakukan di bantaran Sungai Loloan Desa Sanur sepanjang 560 m dengan mengalaisis persepsi dan preferensi masyarakat terhadap taman rekreasi bantaran Sungai Loloan.

\section{Hasil dan Pembahasan}

\subsection{Kondisi Umum Bantaran Tukad Badung}

Taman rekreasi bantaran Sungai Loloan memiliki panjang sungai $560 \mathrm{~m}$ dengan luas keseluruhan kawasan mencapai $5.600 \mathrm{~m}^{2}$. Taman rekreasi bantaran Sungai Loloan terletak pada kawasan Pantai Mertasari Banjar Betngandang, Desa Sanur Kauh, Kecamatan Denpasar Selatan, Kota Denpasar, Provinsi Bali.

Taman rekreasi bantaran Sungai Loloan berfungsi sebagai sarana rekreasi untuk masyarakat Kota Denpasar dan juga sebagai penambah nilai estetika pada Kota Denpasar. Taman rekreasi bantaran Sungai Loloan memiliki daya tarik berupa pemandangan sungai dan juga pantai yang indah.

Taman rekreasi bantaran Sungai Loloan dikelola oleh pemerintah Kota Denpasar yaitu Dinas Pekerjaan Umum Kota Denpasar. Dinas Pekerjaan Umum Kota Denpasar membentuk pasukan biru yang bertugas untuk merawat dan menjaga kebersihan Sungai Kota Denpasar. Pasukan biru berjumlah 219 orang yang disebar di beberapa tempat di Kota Denpasar seperti Sungai Tagtag, Sungai Badung, Sungai Pungawa, Sungai Rangda, Sungai Pekaseh, Sungai Bindu dan Sungai Loloan. Pasukan biru yang bertugas di Sungai Loloan berjumlah 32 orang. Pasukan biru di taman rekreasi bantaran Sungai Loloan selain bertugas membersihkan sungai, pasukan biru juga bertugas merawat tanaman yang ada pada taman rekreasi bantaran Sungai Loloan, antara lain: menyiram tanaman, sesekali memupuk dan memangkas tanaman.

Hasil penelitian mengenai jumlah kunjungan pada taman rekreasi bantaran Sungai Loloan, peneliti melakukan pencatataan jumlah kunjungan selama satu minggu. Setiap harinya dibagi menjadi tiga sesi, yaitu sesi pagi pukul 08.00 sampai pukul 11.00 , sesi siang pukul 13.00 sampai pukul 16.00 dan sesi sore pukul 18.00 sampai pukul 21.00, hingga didapatkan rata-rata kunjungan perhari, perminggu dan per bulannya. Ratarata kunjungan perharinya sebanyak 29 orang pengunjung, rata-rata kunjungan perminggu sebanyak 202 orang pengunjung dan rata-rata kunjungan per bulnya sebanyak 870 orang pengunjung.

\subsection{Persepsi dan preferensi Masyarakat terhadap Taman Rekreasi Bantaran Sungai Loloan}

Pembahasan mengenai persepsi dan preferensi masyarakat terhadap taman rekreasi bantaran Sungai Ioloan ini diperoleh dari menganalisis data kuisioner yang telah diisi oleh responden.

Tabel 1. Aktivitas Responden

\begin{tabular}{lcc}
\hline Aktivitas Responden & Jumlah (orang) & Persentase (\%) \\
\hline Berolahraga & 6 & 20 \\
Jalan-jalan & 3 & 10 \\
Berkumpul & 6 & 20 \\
Memancing & 2 & 7 \\
Menikmati pemandangan & 13 & 43 \\
Total & 30 & 100 \\
\hline
\end{tabular}


Tabel 2. Manfaat Berkunjung

\begin{tabular}{lcc}
\hline Manfaat Berkunjung & Jumlah (orang) & Persentase (\%) \\
\hline Mendapat kesegaran jasmani & 10 & 33 \\
Menambah wawasan & 0 & 0 \\
Menambah pengalaman wisata & 7 & 24 \\
Hiburan & 13 & 43 \\
Tidak mendapatkan manfaat & 0 & 0 \\
Total & 30 & 100 \\
\hline
\end{tabular}

Tabel 3. Fungsi Taman Rekreasi Bantaran Sungai Loloan Menurut Pengunjung

\begin{tabular}{lcc}
\hline Fungsi & Jumlah (orang) & Persentase (\%) \\
\hline Keindahan visual & 9 & 30 \\
Pendidikan & 0 & 0 \\
Tempat olahraga dan bermain & 11 & 37 \\
Tempat bersosialisasi & 4 & 13 \\
Penyedia udara segar & 6 & 20 \\
Total & 30 & 100 \\
\hline
\end{tabular}

Tabel 4. Faktor yang Menyenangkan pada Taman Rekreasi Bantaran Sungai Loloan Menurut Pengunjung

\begin{tabular}{lcc}
\hline Faktor & Jumlah (orang) & Persentase (\%) \\
\hline Teduh / rindang & 7 & 24 \\
Kebersihan kawasan & 10 & 33 \\
Penataan taman yang rapi & 2 & 6 \\
Keindahan pemandangan & 8 & 27 \\
Fasilitas yang memadai & 3 & 10 \\
Total & 30 & 100 \\
\hline
\end{tabular}

Tabel 5. Faktor yang Tidak Menyenangkan pada Taman Rekreasi Bantaran Sungai Loloan Menurut Pengunjung

\begin{tabular}{lcc}
\hline Faktor & Jumlah (orang) & Persentase (\%) \\
\hline Tidak aman & 10 & 33 \\
Tidak nyaman & 3 & 10 \\
Fasilitas tidak lengkap & 14 & 47 \\
Kotor & 3 & 10 \\
Tidak ada & 0 & 0 \\
Total & 30 & 100 \\
\hline
\end{tabular}

Tabel 6. Persepsi Pengunjung Mengenai Keidealan Kawasan Sungai Loloan Dijadikan Taman Rekreasi

\begin{tabular}{lcc}
\hline Keidealan kawasan dijadikan & Jumlah (orang) & Persentase (\%) \\
taman rekreasi & & 10 \\
\hline Sangat ideal & 3 & 37 \\
İdeal & 11 & 53 \\
Cukup ideal & 16 & 0 \\
Kurang ideal & 0 & 0 \\
Tidak ideal & 0 & 100 \\
Total & 30 & \\
\hline
\end{tabular}


Tabel 7. Kondisi Aksesibilitas di Kawasan Taman Rekreasi Bantaran Sungai Loloan

\begin{tabular}{lcc}
\hline Keidealan Aksesbilitas & Jumlah (orang) & Persentase (\%) \\
\hline Sangat baik & 8 & 27 \\
Baik & 17 & 57 \\
Cukup baik & 5 & 16 \\
Kurang baik & 0 & 0 \\
Tidak baik & 0 & 0 \\
Total & 30 & 100 \\
\hline
\end{tabular}

Tabel 8. Preferensi Pengunjung Mengenai Hal-hal yang Perlu Dibenahi pada Taman Rekreasi Bantaran Sungai Loloan

\begin{tabular}{lcc}
\hline Hal yang perlu dibenahi & Jumlah (orang) & Persentase (\%) \\
\hline Kebersihan Sungai & 2 & 6 \\
Kebersihan Pedestrian & 0 & 0 \\
Perbaikan Fasilitas & 3 & 10 \\
Penambahan Fasilitas & 12 & 40 \\
Keamanan Pengunjung & 13 & 44 \\
Total & 30 & 100 \\
\hline
\end{tabular}

Tabel 9. Preferensi Pengunjung Mengenai Elemen dan Fasilitas Taman yang Perlu Ditambahakan

\begin{tabular}{lcc}
\hline $\begin{array}{l}\text { Elemen dan fasilitas } \\
\text { yang perlu ditambahkan }\end{array}$ & Jumlah (orang) & Persentase (\%) \\
\hline Toilet & 3 & 10 \\
Bangku Taman & 8 & 27 \\
Lampu Taman & 9 & 30 \\
Tempat sampah & 8 & 27 \\
Tanaman / Vegetasi & 2 & 6 \\
Total & 30 & 100 \\
\hline
\end{tabular}

Tabel 10. Preferensi Pengunjung Mengenai Vegetasi yang Perlu Ditambahakan

\begin{tabular}{lcc}
\hline Vegetasi yang perlu ditambahkan & Jumlah (orang) & Persentase (\%) \\
\hline Semak & 1 & 3 \\
Perdu & 0 & 37 \\
Pohon peneduh & 11 & 17 \\
Rumput & 5 & 43 \\
Tanaman bunga & 13 & 100 \\
Total & 30 & \\
\hline
\end{tabular}

Tabel 11. Preferensi Pengunjung Mengenai Sarana Penunjang Keamanan yang Perlu Ditambahakan

\begin{tabular}{lcc}
\hline Sarana penunjang keamanan yang perlu ditambahkan & Jumlah (orang) & Persentase (\%) \\
\hline Pemasangan cctv & 10 & 33 \\
Mengadakan petugas keamanan & 9 & 30 \\
Menambahakan pagar pada pinggir sungai & 5 & 17 \\
Pengadaan pelampung & 6 & 20 \\
Tidak ada & 0 & 0 \\
Total & 30 & 100 \\
\hline
\end{tabular}




\subsubsection{Persepsi}

Berdasarkan hasil penelitian persepsi pengunjung terhadap taman rekreasi bantaran Sungai Loloan, sebagian besar pengunjung mempersepsikan taman rekreasi bantaran Sungai Loloan memberikan manfaat sebagai sarana hiburan, olahraga dan rekreasi (Tabel 2) dikarenakan sebagian besar pengunjung taman rekreasi bantaran Sungai Loloan melakukan aktivitas olahraga, bermain dan menikmati pemandangan pada tapak tersebut (Tabel 1$)$.

Pengunjung merasa senang ketika berada di taman rekreasi bantaran Sungai Loloan dikarenakan terjaganya kebersihan pedestrian, kebersihan sungai dan juga keindahan pemandangan taman rekreasi bantaran Sungai Loloan (Tabel 4). Mengenai kawasan Sungai Loloan ini apakah ideal untuk dijadikan taman rekreasi, sebagian besar pengunjung menjawab cukup ideal (Tabel 6) karena lokasi lahan yang strategis terletak di tengah Kota Denpasar dan merupakan salah satu kawasan destinasi wisata, aksesibilitas yang memadai, mudahnya aksesibilitas menuju taman rekreasi bantaran Sungai Loloan juga menjadi nilai lebih, karena aksesibilitas sangat baik, mulai dari kondisi jalan yang baik, lokasi yang mudah ditempuh baik menggunakan kendaraan pribadi ataupun kendaraan umum (Tabel 7) dan juga kondisi alam yang menarik yang memberikan keindahan visual atau estetika (Tabel 3).

Faktor yang menyebabkan berkurangnya tingkat kesenang pengunjung ketika berada di taman rekreasi bantaran Sungai Loloan adalah ketidak amanan pengunjung dan kurangnya fasilitas penunjang taman rekreasi (Tabel 5). Fasilitas penunjang yang kurang antara lain toilet, bangku taman, lampu taman dan tempat sampah (Tabel 9) sedangkan untuk keamanan pengunjung ketika berada pada taman rekreasi bantaran Sungai Loloan antara lain pemasangan cctv, pengadaan petugas keamanan, pengadaan pagar dan pelampung pada pinggir sungai (Tabel 11). Kurangnya fasilitas penunjang taman rekreasi dapat menyebabkan kuranganya minat masyarakat untuk berkunjung ataupun berekreasi ke taman rekreasi bantaran Sungai Loloan. Penelitian tersebut didukung oleh penelitian sebelumnya yang menyatakan minimnya fasilitas penunjang taman rekreasi akan menyebabkan berkurangnya minat pengunjung untuk berekreasi di suatu tempat rekreasi tersebut (Sandy, 2013).

Persepsi masyarakat terhadap taman rekreasi bantaran Sungai Loloan ini sebagaian besar sudah sesuai dengan tujuan pengelola yang membuat taman rekreasi bantaran Sungai Loloan yaitu bertujuan untuk menyediakan sarana hiburan dan rekreasi yang murah serta mudah di akses, namun ada beberapa persepsi masyarakat yang tidak sesuai tujuan pengelola, seperti halnya keluhan masyarakat mengenai keamanan dan fasilitas penunjang lainnya.

\subsubsection{Preferensi}

Berdasarkan hasil penelitian preferensi pengunjung terhadap taman rekreasi bantaran Sungai Loloan, sebagian besar pengunjung menginginkan ditambahkannya fasilitas penunjang yang dapat mendukung kegiatan rekreasi dan juga penunjang keamanan pengunjung di taman rekreasi bantaran Sungai Loloan (Tabel 8) karena memang kurang tersedianya fasilitas tersebut.

Fasilitas yang diinginkan oleh pengunjung antara lain toilet, karena sama sekali tidak ada toilet pada taman rekreasi tersebut, dan juga ingin ditambahkannya bangku taman, lampu taman, tempat sampah karena fasilitas tersebut dirasakan masih kurang (Tabel 9). Tersedianya fasilitas penunjang rekreasi merupakan hal yang paling penting dalam suatu taman rekreasi, karena dengan adanya berbagai fasilitas pengunjung akan merasa betah dan nyaman berada pada taman rekreasi tersebut (Sandy, 2013).

Dari segi estetika pengunjung menginginkan ditambahkannya beberapa tanaman seperti pohon peneduh, tanaman semak dan juga tanaman bunga agar menambah keindahan taman, karena di beberapa bagian taman masih terlihat gersang (Tabel 10). Peneliti merekomendasikan pengelola untuk menanam pohon yang memiliki karakteristik tajuk yang rimbun dan dapat menyerap polusi udara seperti pohon kiara payung (Filicium decipiens) karena pohon ini selain berfungsi sebagai nilai estetika suatu taman, pohon ini memiliki tajuk yang rindang sehingga cocok sebagai tanaman peneduh, juga pohon ini mampu bertahan dikondisi panas yang terik dan mampu bertahan dari terpaan angin yang kencang dan tentunya dapat menyerap polusi udara. Mengenai rekomendasi penambahan tanaman semak, peneliti merekomendasikan tanaman yang dapat menghusir nyamuk seperti halnya tanaman sereh, tanaman tersebut dapat ditanam di dekat tempat duduk maupun gazebo agar pengunjung yang bersantai di tempat tersebut merasa nyaman dan terhindar dari gigitan nyamuk. Pengunjung juga menginginkan ditambahakan tamanan bunga, maka dari itu direkomendasikan 
untuk menanam tanaman bunga yang memiliki karakteristik bunga yang berwarna cerah dan rimbun, cocok ditanam di kondisi panas seperti tanaman bunga kertas (Bougenville), bunga pentas (Pentas lanceolata), dan bunga mandevilla (Mandevilla sp) ketiga tanaman bunga tersebut sangat cocok untuk menambah estetika suatu taman. Ketiga bunga tersebut memiliki bunga yang cukup rimbun, sehingga sangat menarik untuk dilihat, dan juga tanaman tersebut tahan terhadap suhu panas. Estetika atau keindahan adalah salah satu faktor penting sebagai daya tarik wisata (Sandy, 2013).

Dari segi keamanan dan keselamatan pengunjung menginginkan ditambahkannya kamera cctv (close circuit television), juga pengadaan petugas keamanan untuk berjaga di taman rekreasi bantaran Sungai Loloan untuk mengawasi gerak gerik pengunjung yang mencurigakan dan meminimalisir tindakan kejahatan yang mungkin terjadi (Tabel 11). Dalam hal keselamatan pengunjung, pengunjung menginginkan ditambahkan border pagar antara pedestrian dan sungai agar pengunjung lebih aman ketika melakukan jogging ataupun hanya sekedar berjalan di pedestrian dan juga pengadaan pelampung karena sama sekali tidak ada pelampung pada taman tersebut, padahal taman rekreasi bantaran Sungai Loloan terletak pada sungai yang tentunya rawan akan adanya pengunjung yang terjatuh kesungai (Tabel 11). Faktor keamanan dan keselamatanpengunjung merupakan faktor penting di dalam obyek wisata, apabila keamanan dan keselamatan pengunjung telah dijamin oleh pengelola obyek wisata maka pengunjung tidak akan ragu untuk berkunjung pada obyek wisata tersebut (Departemen Budaya dan Pariwisata, 2006).

Preferensi masyarakat ini digunakan sebagai acuan kepada pengelola untuk memaksimalkan keberadaan taman rekreasi bantaran Sungai Loloan. Untuk itu memenuhi preferensi masyarakat adalah hal yang perlu dilakukan oleh pengelola. Hasil ini didukung dengan penelitian sebelumnya Sandy(2013) menyatakan apabila pengelola memenuhi preferensi masyarakat sebagai pengguna taman, maka berdampak berdampak pada meningkatknya minat kunjungan masyarakat.

\subsection{Rekomendasi Penambahan Fasilitas Taman}

Gambar 2a. menunjukkan masih kurangnya fasilitas penunjang taman rekreasi, maka dari itu peneliti merekomendasikan penambahan fasilitas penunjang taman rekreasi bantaran Sungai Loloan berupa penambahan tempat sampah, bangku taman, lampu taman serta penambahan border antara pinggiaran sungai dan pinggiran pedestrian untuk keamanan pengunjung seperti yang ditunjukan pada Gambar 2b.

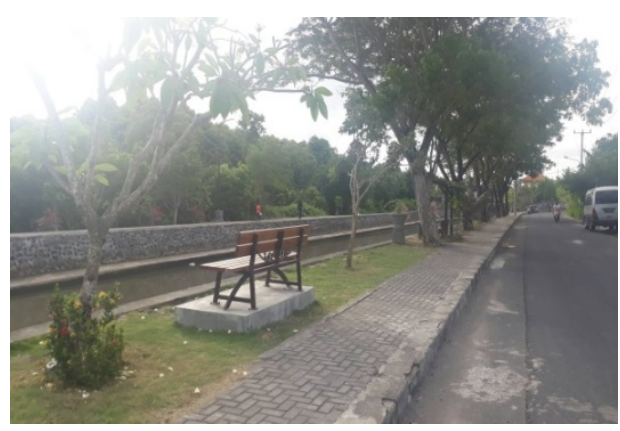

a) Sebelum adanya penambahan fasilitas

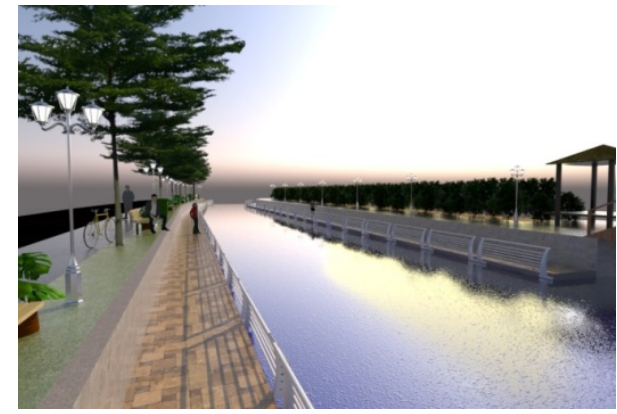

b) Rekomendasi penambahan fasilitas

Gambar 2. Rekomendasi Penambahan Fasilitas

\section{Simpulan dan Saran \\ 4.1 Simpulan}

Persepsi masyarakat terhadap taman rekreasi bantaran Sungai Loloan ini berkategori baik, dikarenakan sebagian besar persepsi pengunjung sesuai dengan tujuan pengelola yang membuat taman rekreasi bantaran Sungai Loloan yaitu bertujuan untuk menyediakan sarana hiburan dan rekreasi yang murah serta mudah di akses, namun ada beberapa persepsi masyarakat yang tidak sesuai tujuan pengelola, seperti halnya keluhan masyarakat mengenai keamanan dan fasilitas penunjang lainnya.

Preferensi masyarakat terhadap taman rekreasi bantaran Sungai Loloan ini adalah masyarakat menyukai dengan keadaan fisik dan visual taman rekreasi bantaran Sungai Loloan. Sedangkan preferensi mengenai manajemen pengelolaan dan keamanan pengunjung sebagaian besar masyarakat menginginkan pengelola melakukan penambahan fasilitas penunjang rekreasi dan fasilitas penunjang keamanan. Preferensi 
masyarakat ini dapat digunakan sebagai acuan kepada pengelola untuk memaksimalkan keberadaan taman rekreasi bantaran Sungai Loloan. Untuk itu memenuhi preferensi masyarakat adalah hal yang perlu dilakukan oleh pengelola.

\subsection{Saran}

Sebagian besar tujuan utama dan fokus perhatian pengunjung di taman rekreasi bantaran Sungai Loloan adalah berekreasi dan menikmati pemandangan taman buatan yang dipadukan dengan pemandangan alami sungai, oleh karena itu pengelola sebaiknya dalam pengembangan daya tarik wisata selanjutnya tetap menjaga kelestarian taman, kebersihan taman dan kenidahan alam yang telah ada. Pengelola juga dapat menghimbau pengunjung untuk ikut serta menjaga kelestarian taman.

Pengelolaan pada taman rekreasi bantaran Sungai Loloan masih kurang baik, untuk selanjutnya diharapkan ada penelitian mengenai sistem pengelolaan taman rekreasi bantaran sungai Loloan, agar nantinya keberadaan taman rekreasi bantaran Sungai Loloan semakin baik.

\section{Daftar Pustaka}

Departemen Budaya dan Pariwisata. 2006. Sadar Wisata dan Sapta Pesona. Departemen Budaya dan Pariwisata. Jakarta 98 hal

Fitri. 2009. Persepsi, Apa Itu? Diunggah dari http://fitri.wordpress.com/persepsi-masyarakat/. Terakhir diakses : 20 September 2016

Kecamatan Denpasar Selatan. 2016. Peta Denpasar Selatan. Denpasar Bali

Reimundo, R. 2014. Mengapa Jumlah Sampel Minimum 30. Diunggah dari http://raynaldoferrarireimundo.blogspot.co.id. Terakhir di akses: 28 Mei 2016

Ruliy. 2009. Persepsi dan Preferensi dalam Perencanaan Tapak. Diunggah dari: http://ruliy.multiply.com/jurnal/item/12. Terakhir di akses: 20 September 2016

Sandy. 2013. Persepsi dan Preferensi Masyarakat Terhadap Taman Margasatwa Ragunan Jakarta. Diunggah dari: http://repository.ipb.ac.id..Terakhir di akses: 5 Mei 2017 